\title{
As antinomias metaéticas entre cegos e não-cegos e o problema do realismo moral
}

\section{The antinomies metaethical between the blind and not-blind and the problem of moral realism}

\section{* Léo Peruzzo Júnior}

\begin{abstract}
Resumo: O presente artigo apresenta o cognitivismo moral pragmático como forma de superar as antinomias clássicas entre cegos e não-cegos e a (im)possibilidade de representação mental do conteúdo moral. Esta posição é sustentada a partir da reconstrução do debate metaético instaurado entre cognitivistas e não-cognitivistas, especialmente nas interpretações fornecidas pelo realismo moral de McDowell e pelo quase-realismo de Blackburn. Assim, o pressuposto comum a essas duas teorias metaéticas [cognitivismo e não-cognitivismo] pretende ser superado pelo cognitivismo pragmático, uma vez que suas falsas dicotomias partem da tese de que todo conhecimento moral é proposicional. Para sanar esse paradoxo, evitamos uma dicotomia radical entre fatos e valores, isto é, não há ações que podem ser valoradas extrinsecamente ao contexto do seu uso.
\end{abstract}

Palavras-chave: Realismo moral. Antinomias Metaéticas. Não-Cognitivismo. Cognitivismo Moral Pragmático.

Abstract: This article presents the pragmatic moral cognitivism as a way to overcome the classical antinomies between blind and nonblind and the (im)possibility of mental representation of the moral content. This position is sustained from the reconstruction of the metaethical debate triggered between cognitivists and non-cognitivists, especially in the interpretations provided by McDowell's moral realism and Blackburn's quasi-realism. Therefore, the common assumption between these two meta-ethical theories [cognitivism and non-

* Professor do Programa de Pós-Graduação Mestrado e Doutorado em Filosofia da PUCPR e da FAE Centro Universitário.<leoperuzzo@hotmail.com> 
cognitivism] intends to be defeated by the pragmatic cognitivism, as their false dichotomies run throughout the thesis that moral knowledge is propositional. To solve this paradox, we avoid a radical dichotomy between facts and values, that is, there are no actions that can be valued extrinsically to the context of its use.

Abstract: Moral Realism. Antinomies Metaethical. Non-Cognitivism. Pragmatic Moral Cognitivism.

\section{Introdução}

A s obras de Diderot Lettre sur les aveules à l'usage de ceux qui voient - Le Lettre sur les sourds et muets à l'usage de ceux qui entendent et qui parlent [Carta sobre os Cegos endereçada àqueles que enxergam e Carta sobre os Surdos e Mudos endereçada àqueles que ouvem e falam $]^{1}$ parecem expressar adequadamente o objetivo de nosso trabalho, isto é, apresentar as rupturas metaéticas entre cognitivistas e não-cognitivistas, sintetizadas, aqui, pela defesa de um cognitivismo moral pragmático. Partindo das percepções e sensações que os cegos experimentam ao contato com objetos reais que não veem, Diderot afirma que os cegos não teriam, necessariamente, a mesma moral que aqueles com pleno uso da visão. Em outras palavras, as atitudes do cego em relação à sexualidade, à criminalidade, à estética, ao horror ou à geometria, por exemplo, teriam outros parâmetros para a representação moral (moral representation). Neste sentido, a assertiva dos argumentos de Diderot permite demonstrar claramente a problemática acerca da possibilidade ou existência de "qualidades morais universais" que deveriam ser cognoscíveis a toda natureza humana. Sendo assim, a partir do paradoxo de Diderot, poderiam ser colocadas as seguintes questões para um defensor de uma posição realista (moral, semântica ou naturalista):

1. se cegos e não-cegos mantêm a mesma "representação moral" acerca de objetos reais, então, as qualidades ou propriedades morais poderiam não depender das experiências físicas;

2. se cegos e não-cegos mantêm a mesma "representação moral" acerca de objetos reais e não-reais (por exemplo, os valores), então, estaríamos discutindo a ética formalmente no plano linguístico, isto é, na esfera metaética;

1 DIDEROT, Denis. Lettre sur les aveules à l'usage de ceux qui voient. Lettre sur les sourds et muets à l'usage de ceux qui entendent et qui parlent. Paris: Flammarion, 2000. 
3. se cegos e não-cegos não mantêm a mesma "representação moral" acerca de objetos reais e não-reais, então, poderíamos dizer que apenas os segundos podem experienciar propriedades morais que são reais;

4. se cegos e não-cegos não mantêm a mesma "representação moral" acerca de objetos reais e não-reais, então, devemos concluir que, da mesma forma que os primeiros, os não-cegos também não podem estar objetivamente seguros das propriedades morais que julgam usar adequadamente;

5. e, por fim, se apenas os não-cegos podem ter "representações morais" verdadeiras, então, deveríamos saber em que sentido tais representações são objetivas e reais, na medida em que se acredita serem físicas, ou, também, se entre eles (não-cegos) as propriedades morais são experiências subjetivas em primeira pessoa (como no exemplo das qualias) ${ }^{2}$.

A resolução destas assertivas reflete, em metaética, o próprio debate instaurado entre cognitivistas e não-cognitivistas. Grosso modo, o cognitivismo moral defende que os predicados éticos (bom, justo, correto etc.) não exprimem qualidades objetivas e secundárias, mas propriedades objetivas e primárias, passíveis de descrição imparcial (por exemplo, o não-naturalismo de $\mathrm{Moore}^{3}$ e McDowell) ${ }^{4}$. Já o segundo, o não-cognitivismo, compreende que os julgamentos morais expressam estados não-cognitivos como emoções e desejos (por exemplo, no emotivismo de Ayer ${ }^{5}$; o quasi-realismo de Blackburn ${ }^{6}$ ou até mesmo o expressivismo de Gibbard ${ }^{7}$ ). Em todas as correntes, devemos considerar como gênese do problema a ruptura realizada por Hume entre fatos e valores, isto é, entre descrições e prescrições. Isso significa que o discurso moral deveria, minimamente, ser considerado absolutamente diferente do discurso proposicional da ciência, uma vez que nesta os fatos devem descrições verdadeiras ou falsas. Do ponto de vista científico, em qualquer caso, os conceitos que interessam são aqueles que se usam com a pretensão de substituir objetos realmente existentes, assim, os

2 Cf. LEWIS, Clarence I. Mind and the World Order. New York: Charles Scribners, 1956. DENNETT, Daniel. Consciousness Explained. Boston: Little, Brown and Company, 1991. A respeito das qualia, Dennett afirma pensá-las como propriedades qualitativas intrínsecas é um erro. O que há são nossos julgamentos, nossas decisões, nossa memória, nossos pensamentos sobre as qualia, e não as próprias qualias enquanto tais.

3 Cf. MOORE, Georg E. Principia Ethica. Cambridge: Cambridge University Press, 1993.

4 Cf. McDOWELL, John. Mind, Value, and Reality. Cambridge, MA: Harvard University Press, 1998.

5 Cf. AYER, Alfred. Are there objective values? In: Freedom and Morality and Other Essays. Oxford: Orxfor University Press, 1984, p.17-34.

6 Cf. BLACKBURN, Simon. Essays in Quasi-Realism. Oxford: Oxford University Press, 1993.

7 Cf. GIBBARD, Allan. Wise Choices, Apt Feelings. Oxford: Clarendon Press, 1990. 
conceitos deveriam ser entidades abstratas não localizadas espaço-temporalmente.

Desta maneira, pretendemos, neste artigo, analisar em que medida é possível falarmos em conhecimento moral sem cairmos num reducionismo fisicalista do conteúdo moral. Para tanto, inicialmente, reconstruímos as posições cognitivistas e não-cognitivistas para, posteriormente, refutar parte de seus argumentos, especialmente aquele que tornaria impossível a discussão sobre a moralidade entre cegos.

\section{É possível falarmos de uma epistemologia naturalizada do conteúdo moral?}

Ao separar a razão das paixões, Hume estabelece que não há um bem supremo ao qual deva se conformar o comportamento humano, da mesma forma que não existem ideias morais inatas dos quais se poderiam derivar regras para as ações humanas. Aliás, se elas existissem, então, a alternativa (1) seria verdadeira. A moralidade é tida como um conjunto de qualidades aprovadas pela generalidade das pessoas, conforme se pode observar na seguinte passagem, na qual Hume indica que:

[...] Talvez se diga que, embora nenhuma vontade ou ação possa contradizer imediatamente a razão, tal contradição pode ser encontrada em alguns dos concomitantes da ação, a saber, em suas causas ou efeitos. [...]. Cabe agora considerar que até que ponto essa verdade ou falsidade pode ser a fonte da moral ${ }^{8}$.

A exortação de Hume procura mostrar que a razão desempenha um papel de correção do sentimento moral no qual, embora cada homem tenha uma posição única no mundo e um ponto de vista próprio, há um nivelamento sobre os diferentes juízos morais. Sem isso não chegaríamos às qualidades aprovadas pela generalidade das pessoas, questão indispensável para o bom funcionamento, por exemplo, da conduta social dos indivíduos na sociedade. Consequentemente, Hume sustenta, e aqui Mackie (1980) está correto, uma espécie de não-cognitivismo moral, uma vez que as paixões tornam os juízos morais "objetivos". Por exemplo, se valoramos algo como bom, mau, agradável etc., esses não seriam traços naturais do mundo $^{9}$, mas qualidades aplicadas pela generalidade humana sobre este.

8 HUME, David. Investigações sobre o entendimento humano e os princípios da moral. São Paulo: UNESP, 2003, p. 126.

9 Cf. MACKIE, John. Hume's moral theory. New York: Routledge, 1980. 
Desta forma, voltando ao problema inicial de nosso artigo, podemos dizer que o problema de Diderot não tem em sua solução uma resposta ética, isto é, possa estar nutrido pela expectativa de que possamos encontrar uma ciência da conduta humana capaz de resolver o dilema entre cegos e não-cegos. Ao contrário, a solução mais própria deveria ser analisarmos o discurso moral resultante do confronto entre as proposituras em questão (entre cegos e não-cegos) para uma possível descrição objetiva dos fatos morais e, com isso, talvez, eliminarmos qualquer propensão em aceitar uma epistemologia naturalizada do conteúdo moral. Em outras palavras, poderíamos aceitar a normatividade das regras morais sem associá-las ou reduzi-las às propriedades primárias dos fatos.

\section{A teoria do erro e a (im)possibilidade de objetividade do conteúdo moral}

Considerando novamente as dicotomias entre cognitivistas e nãocognitivistas, é John Mackie que, na década de 1970, especialmente em Ethics: inventing right and wrong, primeiramente apresenta uma concepção subjetivista e cética sobre a moral. Segundo afirma, os valores morais não serão descobertos, mas construídos; não há valores morais objetivos e as conclusões morais não podem ser derivadas dos significados dos termos morais nem da lógica do discurso moral ${ }^{10}$. Por essa razão, recusando análises metaéticas do tipo emotivista, o autor defende uma aproximação da teoria cognitivista, sustentando que os juízos morais não são redutíveis a simples expressões de sentimentos subjetivos, pressupondo a existência de valores morais objetivos como respostas naturais ao mundo, e que esses poderiam ser usados como critério de correção para nossas ações.

Podemos inferir que a teoria de Mackie centra-se numa base ontológica, a qual é justificada pela ideia que o senso comum é levado a manter falsas crenças morais que são expressas por juízos morais falsos. Essas crenças morais são falsas porque mantêm, a rigor, uma especulação sobre a objetividade das qualidades e propriedades morais. Neste sentido, seria um erro categorial acreditar que pessoas não-cegas podem ter um "senso moral" mais habilitado apenas porque possuem a faculdade da visão. Dizer que "o fato X é moralmente correto" não é uma proposição que possa ser verdadeira ou falsa"; ao contrário, pode ser moralmente justificada apenas pela crença moral sobre o fato em questão. A partir de sua "teoria do erro", Mackie caracteriza, em termos gerais, dois

10 Cf. MACKIE, John. Ethics: inventing right and wrong. London: Penguin Books, 1977, p. 105. 
argumentos a respeito da impossibilidade dos valores serem objetivos: i. a primeira, que todas as afirmações morais são falsas; ii. a segunda, que temos razões suficientes para acreditas que todos os enunciados morais são falsos. Assim, acreditar que nossos julgamentos morais possam ser cognitivos é um erro, uma vez que nossa linguagem e o nosso pensamento não podem representar a objetividade dos acontecimentos do mundo. Em outras palavras, a linguagem, assim como os estados mentais [a consciência], não conseguem capturar a objetividade do mundo, o que significa que podem apenas externalizar reações morais diante dos fenômenos naturais.

A teoria do erro demonstra, portanto, que nos enganamos ao afirmar que há valores morais como se eles fossem objetivos e estivessem realmente presente no mundo como propriedades reais. Neste sentido, Mackie apresenta dois argumentos para sustentar sua posição contra a objetividade dos valores morais que podem solucionar, ao menos aparentemente, a questão da experiência moral entre cegos e não-cegos:

1. argumento da estranheza: alegações morais implicam em um internacionalismo motivacional, isto é, a priori deveria haver disposições motivacionais para executar alguma ação moral; e isso sempre exigiria infinitamente motivações ulteriores (Por que acreditamos que roubar é moralmente errado?);

2. argumento da discordância ou relatividade: não temos razões e justificativas racionais para argumentar contra alguém que esteja disposto a sustentar que certas ações são moralmente corretas ou incorretas (Que tipo de razões devemos fornecer para alguém de que não é correto matar crianças?) ${ }^{11}$.

Enfim, por um lado, primeiramente em oposição aos não-cognitivistas, Mackie considera que o realismo está certo quando compreende que a exigência moral deve ser entendida por sua aparência ou significado manifesto. Isto significa que os predicados morais denotam apenas propriedades genuinamente morais, e não estritamente reais. Por outro lado, Mackie tende a concordar com os não-cognitivistas para a implausibilidade do discurso moral, uma vez que este é pautado numa interpretação não-naturalista. Sendo assim, um argumento prático descrito por Mackie, e que parece ser metodológica e epistemologicamente válido, é a variação moral entre as diferentes comunidades, entre os quais se poderiam destacar os próprios paradigmas históricos construídos por uma centena de fatores. A monogamia, por exemplo, assinalaria a falta de um padrão objetivo na moral. Parece evidente, portanto, que as

${ }_{11}$ Cf. MACKIE, John. Ethics: inventing right and wrong. London: Penguin Books, 1977, p. 105. 
regras morais são apenas modos de agir que espelham os modos de vida instituídos por uma comunidade ${ }^{12}$.

É possível concluirmos, a partir do pensamento de Mackie, que sua visão sobre as proposições morais é, em metaética, defensora do externalismo moral, uma vez que a inexistência de valores objetivos torna dependente da vida comunitária a correção do comportamento e das crenças morais. Segundo Miller, no externalismo, os julgamentos morais não têm uma conexão necessária ou conceitual com as motivações. Isso significa que a inexistência de uma verdade moral objetiva permite concluir que o guia para o comportamento das pessoas deve ser outra coisa, exceto a objetividade dos valores morais ${ }^{13}$.

Neste contexto, para tentar solucionar o paradoxo instaurado pela ausência de objetividade, Mackie desenvolve uma analogia entre os valores morais e as qualidades secundárias, resgatando a terminologia usada na filosofia Locke entre qualidades primárias e secundárias ${ }^{14}$, que representam duas dimensões pelas quais podemos compreender a experiência direta ou a reflexão indireta sobre a realidade. Além de responsáveis por fornecer as ideias que temos sobre o mundo, as qualidades primárias e secundárias desempenham o papel corretivo para os limites do pensamento.

Assim, para vermos que Locke é significativo no debate metaético, o trabalho de Mackie, intitulado Problemas en torno a Locke ${ }^{15}$, procura resgatar a argumentação do filósofo contra as ideias inatas. Conforme Mackie compreende, os capítulos II, III e IV do Livro I do Ensaio, são dedicados a argumentar que não há na mente princípios especulativos como as máximas "É impossível que a mesma coisa seja e não seja" e "O que é, é". Igualmente, não há princípios práticos, morais e, tampouco, ideias inatas, referindo-se que são máximas especulativas porque não se encontram impressas na alma de todos os homens.

Entretanto, como vimos, o neoantirrealismo de Mackie pouco ajudanos a resolver o problema inicial de nosso trabalho [Se cegos e não-cegos devem ter a mesma experienciação moral porque tal questão deve ser pensada em termos objetivos e reais]. A teoria do erro de Mackie é

${ }_{12}$ Segundo Dall' Agnol, "o ceticismo de Mackie não é nem do tipo pirrônico (isto é, nada é afirmado ou negado) nem de um tipo cartesiano (de dúvida universal sobre o conhecimento). Seu ceticismo é uma 'tese ontológica' (Mackie, 1966, p.18): ele nega que há valores objetivos" (DALL' AGNOL, Darlei. Valor Intrínseco: Metaética, Ética Normativa e Ética Prática em G.E. Moore. Florianópolis: UFSC, 2005, p.230).

13 MILLER, Alexander. An introduction to Contemporary Metaethics. Cambridge: Polity Press, 2003.

14 LOCKE, John. Ensaio sobre o entendimento humano. Lisboa: Calouste Gulbenkian, 1999.

15 Cf. MACKIE, John. Problemas en torno a Locke. México: UNAM, 1988. 
válida, porém, para eximir argumentos e traços metafísicos que possam suscitar a necessidade de uma experiência direta com o mundo para sermos capazes de falar em "conteúdo moral objetivo". Se tal premissa fosse verdadeira, então, cegos sempre estariam impossibilitados da compreensão ou significação de regras morais e deveríamos, portanto, passar a discutir o que constitui uma "experiência normal" da realidade.

\section{Entre o cognitivismo moral fraco e o quase-realismo não-cognitivista}

Há duas posições que merecem um resgate, embora talvez não suficiente, para ajudar-nos a responder o debate metaético em questão. A primeira, a posição realista [TR $]^{16}$ de John McDowell ${ }^{17}$; a segunda, o quase-realismo $[\mathrm{OR}]^{18}$ de Simon Blackburn ${ }^{19}$. A divergência entre os autores permitirá mostrar duas questões metaéticas: a primeira, de caráter metodológico, que a posição antirrealista torna o conhecimento moral dependente das qualidades secundárias; e, a segunda, de caráter epistemológico, que o realismo moral pode ser caracterizado como uma rejeição à impossibilidade de objetividade dos valores morais, sustentando que esses dependem de certa percepção e de qualidades que estão no objeto, não podendo serem conhecidas sem que exista uma referência direta à experiência. Sendo assim, podemos situar sete argumentos que traçam o compromisso assumido pelas teorias em questão:

1. a TR sustenta que os valores dependem de nossa experiência moral para serem experienciados; já a teoria OR sustenta que os valores são projeções que não podem ser explicados pela razão, pois estes são apenas sentimentos projetos sobre o mundo natural;

2. a TR apropria-se da ideia de qualidades secundárias para afirmar que a moralidade pode ser concebida como um conjunto de propriedades acessíveis a partir de certos estados subjetivos e, portanto, reais; a teoria $\mathrm{QR}$ critica tal enfoque uma vez que, se os valores não existem como propriedades intrínsecas dos objetos,

16 TR leia-se Teoria Realista.

17 McDOWELL, John. Mind, Value, and Reality. Cambridge and London: Harvard University Press, 2002; McDOWELL, John. Mente e Mundo. Aparecida, SP: Ideias \& Letras, 2005.

18 OR leia-se Teoria Quase-Realista.

19 BLACKBURN, Simon. Essays in Quasi-Realism. New York: Oxford University Press, 1993; BLACKBURN, Simon. Verdade: um guia para perplexos. Rio de Janeiro: Civilização Brasileira, 2006. 
e se os mesmos são qualidades aplicadas sobre eles, então, dependeriam sempre do grau de eficiência de nossa experiência moral em condições "normais";

3. a TR defende uma ética de virtudes e compreende que a mesma expressa um tipo de conhecimento moral, uma forma que permite coordenar antecipadamente o resultado moral das ações futuras. Sendo assim, a virtude não é um hábito, mas uma capacidade de decisão sobre algo moralmente correto ou falso. Já a teoria $Q R$ afirma que as propriedades avaliativas são projeções de nossos próprios sentimentos, emoções, atitudes etc., não havendo nada de superveniente aos fatos;

4. a TR sustenta que só podemos compreender um conceito e, consequentemente, realizar a aplicação correta de um juízo, utilizando como pano de fundo uma prática pré-estabelecida. A teoria $\mathrm{QR}$, ao contrário, mantém uma visão naturalista, no sentido de que tenta ver o homem como parte da natureza e tenta explicar a moralidade como decorrente da sua própria natureza e situação;

5. a TR utiliza-se do arcabouço teórico de Wittgenstein e sua concepção de "seguir uma regra". Neste caso, as regras são construções sociais de certa prática ou conduta, pressupondo que conforme seguimos uma regra está pressuposto um conhecimento implícito dela. A teoria $\mathrm{OR}$ admite a manutenção da visão nãocognitivista do Tractatus nas Investigações, sendo que "seguir uma regra" [moral, por exemplo] é apenas um processo automático derivado, em grande medida, no hábito;

6. na TR as regas não podem ponderar sobre a natureza da decisão moral; a capacidade de ação depende do agente virtuoso. Para o QR, a moralidade é superveniente ao mundo; adornamos e manchamos o mundo, como se ele tivesse características [morais] para responder aos nossos sentimentos e projeções;

7. e, por fim, a TR parece não explicar como uma pessoa pode fornecer razões para si mesmo que está seguindo a regra, porém não consegue fornecer razões para outra de que sabe que está seguindo a regra corretamente. Por outro lado, segundo a teoria $\mathrm{OR}$, a crença moral não pode ser identificada com nenhuma propriedade moral, mas com propriedades naturais projetadas sobre o mundo.

As objeções entre a TR [de McDowell] e a teoria OR [de Blackburn] permanecem distantes da resolução do problema metaético entre cegos e não-cegos, a saber, se cegos poderiam ter a mesma experienciação moral de alguém que possui a visão, ou ainda, se podemos falar em 
objetividade na percepção de fatos morais. Aceitando qualquer uma das premissas, somos levados, pelas teorias em questão, a um nível de discussão empírica que exigiria falarmos sempre em condições normais de experienciação da natureza e, portanto, de atribuição de valor sobre os fatos. Embora esta seja uma premissa importante, o debate pode ser, em grande medida, dissolvido pela análise do conteúdo linguístico que utilizamos para expressar nossos juízos morais. Por sua vez, devemos migrar o dilema entre cegos e não-cegos [e o debate entre cognitivistas e não-cognitivistas] para a análise de como nossas proposições, sentenças, juízos e conceitos funcionam e, consequentemente, adquirem significação.

Resumidamente falando, a TR apela para a experiência moral como um elemento subjetivo; logo, cegos estariam sempre numa desvantagem [filosófica] frente a certas avaliações morais como, por exemplo, nas técnicas de crueldade que foram aplicadas sobre uma vítima. Já a teoria $\mathrm{OR}$, ao afirmar que fazemos naturalmente projeções sobre o mundo, não consegue explicar por que fazemos certas projeções avaliativas ao invés de fazermos outras, isto é, haveria uma intencionalidade natural não racional no momento em que fazemos certas projeções ${ }^{20}$. Isso significaria, para a teoria $\mathrm{OR}$, que tanto um cego como um não-cego deveriam sempre explicar as motivações das suas motivações, o que tornaria o debate um regresso ad infinitum.

\section{Por que o cognitivismo moral pragmático poderia responder ao problema da experienciação moral entre cegos e não-cegos?}

O pressuposto comum a essas duas teorias metaéticas [cognitivismo e não-cognitivismo] partem da tese de que todo conhecimento moral é proposicional o que, portanto, prolifera a expectativa de eliminação dos discursos não-formais. Para sanar esse paradoxo, evitamos uma dicotomia radical entre fatos e valores, isto é, não há ações que podem ser valoradas como, por exemplo, certas ou erradas, corretas ou incorretas, extrinsecamente ao contexto do seu uso. Na verdade, Putnam já alertara para um ponto de vista adotado erroneamente desde o século XVII a respeito da percepção: "A questão 'como é que a linguagem se encaixa no mundo?' é, no fundo, uma repetição da antiga questão 'como é que a percepção se encaixa no mundo?'"21. Desta maneira, concordando com Putnam, a indicação de uma dualidade entre linguagem \pensamento, linguagem\realidade \, pensamento\realidade ou fato\valor são resquícios de um velho pseudoproblema.

20 BLACKBURN, Simon. Essays in Quasi-Realism. New York: Oxford University Press, 1993.

21 PUTNAM, Hilary. A Tripla Corda: Mente, Corpo e Mundo. Lisboa: Instituto Piaget, 1999, p. 35. 
Assim, acreditamos que o cognitivismo moral pragmático pode indicar-nos certas escadas para superar o problema em questão, mas que, posteriormente, também devem ser abandonadas pelo seu interlocutor. Seguindo o pensamento de Wittgenstein, e abandonando a construção de uma linguagem ideal, própria do Tractatus e reassumida pela interpretação do Neopositivismo Lógico [especialmente Carnap], é significativo considerarmos alguns argumentos para dissolver o debate tradicional entre cognitivistas e não-cognitivistas:

1. toda justificação do conteúdo moral só ocorre pela existência de uma natureza comunicativa dos falantes; o conteúdo moral, portanto, não pode ser pensado apenas de forma fisicalista, isto é, em sentido proposicional;

2. o debate sobre a existência de propriedades ou fatos morais é falsa pois, se existissem, deveriam ser algo absolutamente diferente das propriedades físicas existentes no espaço e no tempo (e não saberíamos como observá-los, assim como temos dificuldades para observar o átomo, a "realidade", entre outros elementos);

3. a compreensão é um fenômeno linguístico e não-linguístico (por exemplo, o processo de compreensão dos surdos) que permite o progresso da interação entre os falantes; em outras palavras, o conteúdo moral torna-se cognitivo na medida em que ele passa a ser entendido por meio de uma representação mental que, não necessariamente, precisa utilizar-se de "imagens";

4. embora possamos identificar uma variação significativa dos códigos morais, o que poderia influenciar a defesa de um ceticismo moral ou de uma teoria não-cognitivista, a forma de vida humana deve ser considerada uma pré-condição para a discussão de qualquer questão em nível metaético. Neste sentido, não podemos falar em significado do conteúdo moral, mas em termos de compreensão e competência observável [de cegos ou não-cegos];

Sendo assim, procuramos mostrar que tanto a posição metaética do cognitivismo como aquela do não-cognitivismo moral passam ao lado de uma interpretação adequada do "discurso e do conteúdo moral". Dizer que um juízo moral é objetivo e, portanto, cognitivo, exige aproximar tanto a objetividade dada pela regra, quanto a objetividade dada pela realidade. Mesmo assim, isso não significa dizer que um juízo é cognitivo porque é verdadeiro ou falso, mas, ao contrário, é cognitivo porque encontra no contexto (e aqui o uso do termo pragmático) um uso efetivo que confere a compreensão entre os falantes "verdadeira". Neste sentido, os próprios conceitos morais são conceitos linguísticos e, por isso, não se pode 
pensá-los como derivados de um mundo extra-humano. Precisamos, portanto, utilizando-nos dos termos wittgensteiniano ${ }^{22}$, analisar a gramática moral de nosso discurso e vê-la além de uma estrutura proposicional.

Sob essas condições, acreditamos que Luckhardt está certo ao afirmar que no jogar do "jogo de linguagem da valoração moral não se define uma ação como imoral, sem alguma razão; ao contrário, devemos estar [...] prontos para explicar os motivos pelos quais se aplica tal termo"23. Quer dizer, os padrões morais de uma cultura são explicados aos seus membros dando-lhes possibilidade para dizer que uma ação é justa ou injusta. Consequentemente, se perguntarmos a esses membros se os padrões morais são justos ou injustos, a resposta certamente buscará fora um novo standard para justificar e validar esses critérios. Assim, a partir da posição de Luckhardt é possível defender que, numa leitura wittgensteiniana, a posição dos relativistas éticos é incoerente e absurda, uma vez que não podemos decidir sobre os sistemas morais da mesma forma que respondemos a questões sobre teorias físicas ${ }^{24}$.

\section{Considerações}

Como consequência dos argumentos apresentados, acreditamos que o cognitivismo moral pragmático dissolve a vagueza e o mito da objetividade empírica na flexibilidade que os conceitos e juízos morais adquirem nos jogos de linguagem que fazem parte da forma de vida humana. Neste caso, se não dependemos exclusivamente da percepção e da realidade para formular nosso conteúdo moral, é analiticamente falso o argumento de que cegos não poderiam ter uma "sensibilidade moral". Aliás, se tal premissa fosse incondicionalmente verdadeira, então, deveríamos primeiramente discutir se a "percepção" é universal ou apenas uma "representação cerebral", e, posteriormente, acreditar que uma deficiência na natureza (por exemplo, visual) reduziria a atitude moral e o comportamento de alguém (os óculos, portanto, seriam sinônimo e início da imoralidade).

\section{Referências}

AYER, Alfred. Are there objective values? In: Freedom and Morality and Other Essays. Oxford: Orxfor University Press, 1984.

22 Cf. WITTGENSTEIN, Ludwig. Investigações Filosóficas. Petrópolis, RJ: Vozes, 1996.

${ }^{23}$ LUCKHARDT, Carol G. Wittgenstein e il relativismo ético. In: ANDRONICO, Marilena; MARCONI, Diego; PENCO, Carlo. Capire Wittgenstein. Genova: Marietti, 1996, p. 301.

24 Idem, p. 302-303. 
L. Peruzzo Júnior - As antinomias metaéticas entre cegos ...

BLACKBURN, Simon. Essays in Quasi-Realism. Oxford: Oxford University Press, 1993. . Verdade: um guia para perplexos. Rio de Janeiro: Civilização Brasileira, 2006.

DALL ' AGNOL, Darlei. Valor Intrínseco: metaética, ética normativa e ética prática em G.E. Moore. Florianópolis: UFSC, 2005.

DENNETT, Daniel. Consciousness Explained. Boston: Little, Brown and Company, 1991.

DIDEROT, Denis. Lettre sur les aveules à l'usage de ceux qui voient. Lettre sur les sourds et muets à l'usage de ceux qui entendent et qui parlent. Paris: Flammarion, 2000.

GIBBARD, Allan. Wise Choices, Apt Feelings. Oxford: Clarendon Press, 1990.

HUME, David. Investigações sobre o entendimento humano e os princípios da moral. São Paulo: UNESP, 2003.

LEWIS, Clarence I. Mind and the World Order. New York: Charles Scribners, 1956.

LOCKE, John. Ensaio sobre o entendimento humano. Lisboa: Calouste Gulbenkian, 1999.

LUCKHARDT, Carol G. Wittgenstein e il relativismo ético. In: ANDRONICO, Marilena; MARCONI, Diego; PENCO, Carlo. Capire Wittgenstein. Genova: Marietti, 1996.

MACKIE, John. Ethics: inventing right and wrong. London: Penguin Books, 1977. . Hume's moral theory. New York: Routledge, 1980. . Problemas en torno a Locke. México: UNAM, 1988.

McDOWELL, John. Mente e Mundo. Aparecida, SP: Ideias \& Letras, 2005. 2002; . Mind, Value, and Reality. Cambridge and London: Harvard University Press,

MILLER, Alexander. An introduction to Contemporary Metaethics. Cambridge: Polity Press, 2003.

MOORE, Georg E. Principia Ethica. Cambridge: Cambridge University Press, 1993. PERUZZO JÚNIOT, Léo. Wittgenstein: o interior numa concepção pragmática. Curitiba: Editora CRV, 2012.

PUTNAM, Hilary. A Tripla Corda: mente, corpo e mundo. Lisboa: Instituto Piaget, 1999, p. 35.

WITTGENSTEIN, Ludwig. Investigações Filosóficas. Petrópolis, RJ: Vozes, 1996.

\section{Endereço postal:}

Escola de Educação e Humanidades

Rua Imaculada Conceição, 1155

Curitiba, PR, Brasil

Data de recebimento: 23/04/2015

Data de aceite: 12/03/2016 